\title{
Responding to Uncertainties in COVID-19 with Real Options: The Per- spective of Governments
}

\author{
Terhi Chakhovich* and Saija Marttila
}

Aalto University, School of Business, Department of Accounting PL 11000, 00076 Aalto, Helsinki, Finland.

\begin{abstract}
COVID-19 has affected people, businesses and governments worldwide, causing widespread uncertainty in the business world. Here we look at COVID-19 uncertainty using the tool of real options. We focus on the perspective of governments, particularly the Finnish Government, which in its decisions has endeavoured to keep many of its options open in this situation. We describe the real options relevant here, how uncertainty impacts them and also how selected cognitive biases may influence the decisions through the use of such real options. The real options discussed are the option to delay, the time-to-build option, the option to alter scale and the option to switch. The cognitive biases relevant here are the status quo bias and the confirmation bias. The study extends the research on real options by scrutinising a highly topical case. The study also offers guidance to governments on how to respond to the COVID-19 crisis. Moreover, the study provides suggestions on how to evaluate governmental decisions in the COVID-19 crisis. This study addresses a highly topical phenomenon, the COVID-19 crisis, in order to shed light on how real options can be used as a tool to analyse such a crisis.
\end{abstract}

Keywords: COVID-19, government, real option, uncertainty.

\section{INTRODUCTION}

Uncertainty is omnipresent in today's world. For example, international trade, new technologies and the speed of information transfer have made the future more uncertain. (Teece and Leih, 2016) Epidemics, including the COVID-19 pandemic, which is currently shaking the whole world, also increase the uncertainties and make it extremely difficult to predict the future (Fair et al., 2012).

Uncertainty has traditionally been perceived as problematic, for example, in the investment context: the greater the uncertainty, the smaller is the expected payoff from the investment. However, in the context of real options, this relation can be reversed: real options are more valuable the more uncertainty there is. (Busby and Pitts, 1997) Options are only valuable when there is uncertainty about the future states of the world. Relatedly, Verbeeten (2006) found that companies facing high levels of financial uncertainty (particularly regarding exchange rates and interest rates) used more sophisticated innovation evaluation techniques such as real options. If a decision-maker knows what will happen in the future, there is no need to consider real options. A context fraught with uncertainty, such as the COVID-19 crisis, is therefore beneficial for studying the use of real options. We also acknowledge that there are different types of real options and different types of uncertainties, each of which may or may not be relevant in the case of the COVID-19 crisis. This crisis may have served as a fertile ground for the creation of

*Address correspondence to this author at Aalto University, School of Business, Department of Accounting PL 11000, 00076 Aalto, Helsinki, Finland; Tel.: +358-40-574-3064; E-mail address: terhi.chakhovich@aalto.fi valuable real options or it may have caused uncertainties that have not materialised in valuable real options.

The small Northern European country Finland (population of about 5.5 million) has an open economy heavily dependent on other economies in terms of imports and exports, particularly of goods but also of services. As empirical data this paper relies on the publicised Finnish Government messaging about the COVID-19 crisis from the beginning of March 2020 until the present. This messaging has been gathered mostly from articles in the public press.

In the case of companies, COVID-19 seldom provides a variety of real options. On the one hand, many companies may simply be forced to shut down their operations, possibly with no means to create options or keep options open. On the other hand, companies selling necessities, for example groceries, have options to expand. However, the variety of options open to companies is more limited than to governments and in order to bring this variety out into the open this paper focuses on the decisions of governments. The Finnish Government is used here as a representative example of governments. We also look at the implications for companies and individuals when this sheds light on governmental decisions.

Below we will first describe the causes of uncertainties generally and in relation to the COVID-19 crisis. We will then look at four real option types, their relevance in the current situation, how the causes of uncertainties affect which real option type is relevant and how each type of option could be used. The real options discussed are the option to delay, the time-to-build option, the option to alter scale and the option to switch. We then look at two cognitive biases prevalent in real options and the COVID-19 crisis and present sugges- 
tions on how such biases could be avoided or their effects mitigated. The cognitive biases discussed are the status quo bias and the confirmation bias. We end with conclusions and suggestions for new research directions.

\section{CAUSES OF UNCERTAINTIES IN THE COVID-19 CRISIS}

The uncertainty in the COVID-19 crisis has been severe, global and multidimensional. The Finnish Government has also faced extreme uncertainty in the case of the COVID-19 crisis. Finland has never before been in such a situation and the new, unprecedented circumstances increase the uncertainty even more. In spring 2020, a state of emergency was declared and the Government resorted to extreme measures in the form of the Emergency Powers Act.

Zimmermann (2000) has identified six causes of uncertainty and all of them are present in the COVID-19 crisis. The first and probably the most important cause in this case is the lack of information. The Government initially did not have enough information about the virus: its speed of spreading, the likely duration of the pandemic, the number of virus carriers, or the actions needed to control the virus. Decisions are very difficult to make if there is not enough information about the consequences of actions. In spring 2020, the Government introduced a lockdown during which all nonessential services necessitating any contact between people were brought to a halt, schools and restaurants were closed and restrictions imposed on travel. The lockdown was relaxed in summer 2020 but many restrictions remain and have been recently tightened. Uncertainties remain, for example, regarding the number of people in intensive care, the capacity of hospitals, and the consequences to the economy in the future.

Uncertainty can also be caused by abundance of information (Zimmermann, 2000). By now, the virus has been extensively studied. However, due to bounded rationality or time constraints, people are incapable of processing an extensive amount of information and for this reason some of it will not be properly utilised (Karr-Wisniewski and $\mathrm{Lu}, 2010$ ). The Government has faced and will continue to face uncertainty due to information overload. Because the virus spreads fast, actions have been and may still be needed on a relatively fast schedule and not all studies on actions in other countries can be read thoroughly. New information becomes available every day and the Government may not be able to react fast to this information.

New information is needed, and new studies and expert opinions are published regularly. However, the information may be inconsistent: uncertainty may be caused by conflicting evidence (Zimmermann, 2000). When expert opinions vary, the actions to stop the virus from spreading are uncertain. Experts may have many differing opinions and there are no right or wrong answers. The fourth cause of uncertainty is beliefs (Zimmermann, 2000). Decision-makers may entertain their own beliefs about the virus and use these to simplify the decision-making in uncertain situations, which may lead to erroneous decisions which again increase uncertainty. People may assume, for example, that the virus spreads easily on surfaces or through water as do some other viruses but the Finnish Institute for Health and Welfare has announced that COVID-19 mainly spreads through air.

Ambiguity and measurements are also causes of uncertainty according to Zimmermann (2000). Ambiguity is caused by linguistic differences. Because COVID-19 is a global pandemic, research is implemented in multiple languages, and something may be lost in translation. In the COVID-19 crisis, uncertainties caused by measurements are mostly errors in testing for infection. However, these two causes are not as relevant as the other four when trying to understand the real options in the decision-making about the COVID-19 crisis.

The causes of uncertainties should be analysed so that the uncertainties can appropriately be addressed. Decisionmakers may think that they do not have enough information about the corona virus when actually there is ample information available, but it is not known how to use it or the information is not organised properly so that it can be used. Of course, there is not enough information on every aspect of the virus, but there are already data, for example, on how countries have reacted to the virus and some of the causes for and effects of those actions. If the uncertainties are due to lack of information, more information could be gathered to reduce uncertainty (Zimmermann, 2000). However, if the reason for the uncertainty is information overload, this cannot be solved by gathering yet more information but rather by organising the existing information. Moreover, when the evidence is conflicting, uncertainty is not reduced by gathering even more information or organising the information but by acknowledging and correcting the false evidence.

\section{THE USE OF REAL OPTIONS}

Uncertainty may be difficult to take into consideration in decision-making and decision-making is more challenging in uncertain situations. One way to observe and manage uncertainty is the use of real options (Dixit and Pindyck, 1994). Real options are mostly used when analysing the profitability of strategic investments in companies (Tavles et al., 2007; McGrath and Nerkar, 2004; Verbeeten, 2006). Real options are alternatives and opportunities that create flexibility in investment processes (Dixit and Pindyck, 1994) and are typically used to support other investment calculation methods (Verbeeten, 2006, p. 107). With real options the executives of a company can build flexibility into their investments, take the strategic alternatives of an investment into consideration when uncertainty is present and change the investment when uncertainty is reduced (Mun, 2006).

Real options as a decision-making tool for investments are most beneficial when uncertainty is high (Busby and Pitts, 1997). In the real option approach, uncertainty and thus risks, are acknowledged to create value for investments (Mun, 2006). Accordingly, Miller and Waller (2003) and Busby and Pitts (1997) treat real options as a part of risk management.

Real options have usually been analysed from a corporate perspective as a formal method of investment analysis (Tayles et al., 2007; Dixit and Pindyck, 1994; McGrath and Nerkar, 2004). As an example from the health sector McGrath and Nerkar (2004) study real options in pharmaceutical companies. Tayles et al. (2007) look at how firms 
with a relatively strong emphasis on structural intellectual capital are relatively more likely to consider a real options approach in their investment decisions.[1] Johnston et al. (2008) consider how financial markets value real options in companies' businesses. Baldenius et al. (2016) look at how the ability of a company to delegate investment decisions to its managers by using selected performance measures is affected by the real options available.

Bowman and Moskowitz (2001) point out that the formal use of real options requires any associated models to be adjusted to the situation of each organisation. This makes the actual application of real options models demanding. Here we apply the model only at the level of decision-making in general, not using actual numbers. Another potentially problematic aspect of real options is that managers may have difficulties in committing the organisation to actions if no decisions are taken and options are kept open (Busby and Pitts, 1997).

With the help of real options uncertainty can be analysed more effectively (Miller and Waller, 2003). The Government could use real option thinking to assess the possible alternatives and analyse the outcomes of uncertain events when facing the COVID-19 crisis. The use of real options by the Government differs somewhat from a company analysing its real options. Uncertainty may not create value in the COVID-19 crisis as it does when analysing an investment, but this uncertainty undoubtedly adds to the number of possible actions available to respond to the crisis. Companies focus mainly on the financial benefits of a decision, aiming at profitable investments, whereas the Government focuses on minimising the harm caused by the disease: reduction of infections and minimisation of economic losses.

The Finnish Government decided to try to prevent the spread of the virus and "flatten the curve" by means of a lockdown. The Government has kept its real options open and maintained flexibility in decision-making. Then the Government started to gradually end the lockdown in summer 2020 and real option thinking could also become useful for that action. There are many different ways to exit the lockdown and real options can be used to structure both the actions and the uncertainty. Trigeorgis (1995) has typified real options and some of these real option types presented below are useful when exploring the possible actions.

\section{The Option to Delay}

By prolonging lockdowns the Government can gather more information about the disease, organise the information available or wait until the uncertainty abates. The Government can wait and see how other countries manage to exit lockdowns and what kind of consequences their actions have, thus emulating the best practises. Prolonging the lockdown is not only useful for getting more information but also for getting ready for the spread of the disease. By prolonging the lockdown, the Government for example allows the hospitals more time to be ready for the spread of the disease and the schools to organise their premises so that children can attend classes safely.

The option to delay is most useful when the source of the uncertainty is a lack of information. This option gives deci- sion-makers time to gather information. However, the option to delay is also useful when other causes of uncertainties are present. When the source of uncertainty is abundance of information, this option gives time to organise the information. When the source of uncertainty is conflicting evidence, this option gives time to go through the information to identify the false "information". When uncertainty is caused by beliefs, this option gives time to receive information to support any subjective claims with objective proof or to prove that the beliefs are incorrect.

This option could also be misused. Time to delay may be lacking if human lives are at stake. Having too much information actually means having information to base decisions on. In many situations the uncertainty may not disappear with the delay. However, in the case of the COVID-19 crisis, we receive new information continuously as countries try different strategies and thus the option to delay seems valuable here.

However, delaying may also be just an excuse to avoid decision-making. The status quo may seem an attractive option because at least the present is known while the future may be unknown. However, as the virus situation changes constantly, retaining the status quo in a country with an open economy may not be a viable option in the medium to long term.

With a lack of information the option to delay is of value as delay provides more time to receive more information. When the source of uncertainty is too much information, beliefs, or contradictory evidence, simply waiting will not resolve the uncertainty but other actions are required. Members of the Government may think that the source of uncertainty is the lack of information when another source is actually present (excess of information, beliefs, contradictions), and such members of the Government may thus not understand that they need to act themselves to resolve the uncertainty. Keeping options open by not acting may appear a viable way forward, while action may actually be the best strategy even if certain options are thus exercised. The kind of action needed would also be more about organising information, action that does not result in many options being exercised.

\section{The Time-to-Build Option}

With the time-to-build option the exit from the lockdown can be divided into smaller steps instead of relaxing all the restrictions at once. The idea of the time-to-build option is that the next step will be taken only if the outcome of the previous step is as desired. The Government can decide to first open primary schools and if the spike in the infections is not overly high, then decide whether the secondary schools and other educational institutions should be opened. The same gradual approach fits the opening of other services like public sports centres and restaurants.

When the source of the uncertainty is the abundance of information, the time-to-build option allows beginning the decision-making process with a relatively minor decision. During this first step, the decision-makers may have more time to organise the information. After the first step, the decision-makers can analyse the information again - maybe some of the uncertainty has disappeared. 
If the source of the uncertainty is lack of information, this option may also be valuable. If there is enough information to start opening lockdowns in the first place, more information can be gathered during the process on how the process can be continued. For example, one could first open the primary schools and then decide whether telework should still be favoured.

The time-to-build option may not be useful when the uncertainty is caused by beliefs. Arguably the decisions in the COVID-19 crisis should not be based on beliefs and subjective opinions only. This option may also not be useful when the source of the uncertainty is conflicting evidence - then the risks of making decisions may be unacceptably high. Moreover, the evidence may continue to be inconsistent, even if more evidence is collected. Decisions must sometimes be made even though the evidence is conflicting.

\section{The Option to Alter the Operating Scale}

When altering the operating scale in response to the COVID19 crisis, the Government can encourage companies and other players to invent alternative ways to open their businesses and activities. In this situation exiting the lockdown would not mean going back to "normal living" but discovering ways to eliminate the restrictions in a safer way. Businesses can scale their products and services into new areas. For example, as restaurants were shut down so that people would not gather in large groups in small spaces, restaurants which previously did not provide takeaway food or home delivery could now modify their businesses and provide home deliveries to avoid having to shut down their entire businesses. People who used to work as taxidrivers could expand their businesses by delivering food and other products. Sports centres could open online services or relocate their activity outdoors. Naturally, altering the scale or discovering new ways for the businesses to function is not always effective or profitable. In the case of an entrepreneur who has no knowledge of software, the digitalisation of services may prove very difficult.

When the source of the uncertainty is lack of information, the planning of alternative ways to do business can begin even if there is not enough information about the future. It is beneficial to be prepared for many different outcomes. When the source of the uncertainty is conflicting evidence, the Government may not know whether to continue the lockdown or partially end it, and it is good for businesses to be prepared for both scenarios.

\section{The Option to Switch}

There is also an option to switch the COVID-19 crisis strategy. In summer, Finland's COVID-19 strategy was to halt the spread of the pandemic. Through the lockdown the Government has retained its flexibility, which enables it to consider alternative strategies. Finland could, for example, try to achieve herd immunity and completely end any lockdowns or tighten the lockdown measures and implement a curfew for the citizens - or do something in between.

The option to switch the COVID-19 crisis strategy is valuable, especially when the evidence is conflicting or there is lack of information. The Finnish Government reacted to the new information on the COVID-19 relatively fast in spring 2020. If the uncertainty due to conflicting evidence is resolved, the Government can again react to the situation rapidly thanks to The Emergency Powers Act and, for example, reinstate lockdowns.

\section{COGNITIVE BIASES TO AVOID}

Humans' cognitive processing is limited because of bounded rationality (Jolls et al., 1998). When analysing uncertainties and planning the measures in the COVID-19 crisis, cognitive biases, which are systematic errors in decision-making, should be taken into consideration and the decision-makers should try to avoid them by becoming aware of them. One of the best-known biases in an uncertain situation is called the status quo bias: people try to avoid uncertainties by accepting the current circumstances even though uncertainty is still present (Das and Teng, 1999).

The danger of the status quo bias lies in the decision-makers becoming paralysed in the current situation because the consequences of actions are uncertain. For example, decisionmakers may be afraid to end lockdowns for fear of new corona cases or, once lockdowns have been ended, they may be afraid to reinstate them, even though there may be a new spike in infection. Having options can cause the status quo bias if decision-makers are afraid to exercise their options. The current situation may feel safe because at least the decision-makers then know what the situation is. Naturally, the Government should scrutinise different uncertainties and make decisions even though the future remains uncertain and not just try to cling to the current situation.

Another well-known bias to avoid in the COVID-19 crisis is the confirmation bias. This means that people have a tendency to only search for information which corroborates their personal beliefs (Kappes et al., 2020). To avoid this, any information available should be evaluated as objectively as possible and information contrary to one's own opinions should also be sought and acknowledged.

The risk in the confirmation bias is that humans may search for information which only supports and justifies their own pre-existing beliefs. For example, regarding the use of facemasks, there may be a false belief: "The masks protect us from the virus so we can live a normal life and go to crowded places when wearing a mask as the virus spreads by droplets." The masks may only be a way to reduce the speed of the spreading of the virus. In addition, it is often not enough to just wear a mask. It needs to be worn correctly and not every mask is effective. Governments would do well to consider and motivate against such biases.

Real options can be used to mitigate the biases. With an option to delay, the decision-makers have more time to assess the situation and gather or structure the information - and maybe find other options as well, not only the ones they want to see. The time-to-build option makes it possible to divide the action of ending the lockdown into smaller steps. After the first step has been taken, the decision-maker may see the situation in a new light, preferring to transfer to Plan $\mathrm{B}$, also mitigating the status quo bias.

The decision of the Finnish Government has been seen as that between two static options: "flatten the curve" and "get 
herd immunity sooner". But "flatten the curve" is also about keeping real options more open. The decision is not one-time but could be about retaining flexibility for the future. Members of the Government may be attracted to the idea of having many options and for that reason they may prefer to "flatten the curve", not only because it appears more longterm oriented and could thus be perceived as better. The Government may have an idea that it is good to have options open but no immediate use for them may be seen. However, here the risk is that one ends up doing nothing; having the options but not exercising them; and thus also reducing the commitment of citizens (Busby and Pitts, 1997). Delaying the epidemic retains the options and this becomes possible once "flatten the curve" has been chosen. Ending all lockdowns exercises the options somewhat. However, there is always the chance to reinstate a lockdown. Real options are also created along the way, for example when ordering of protective masks and freeing hospital beds allows flexibility for when the situation becomes more dire.

When decision-makers possess real options, the situation appears to be more under their control than if all the options had been exercised. Real options can be maintained for oneself or one's own party or for the country (members of a future government). The situation is now such that real options have been created and come to be exercised. The question is when and how to exercise them to the best effect.

Real options can also feel like an international burden. Imagine a situation in which Finland would maintain the lockdown and try to approach the epidemic very carefully while Sweden would have no lockdown. Swedes may wish to migrate to Finland to avoid the illness if the border is not closed. Sweden may then accuse Finland of keeping their options open if Finland closes the border. The creation of real options regarding the epidemic in Finland would thus force the Finnish Government into deciding if it should close the border, which may be detrimental to international relations. Finland may have to choose which real options it prefers: those that allow flexibility regarding the illness and its containment, or those that allow for flexibility in international relations.

\section{CONCLUSIONS}

Real options afford opportunities for governments to evaluate their own decisions and actions and provide tools to avoid common biases in decision-making. Real options can also be used as a tool by outside observers to evaluate governmental decisions and actions.

The Black-Scholes option pricing formula indicates which factors affect options pricing. The factors are time to expiration (which could be a long time in the case of the COVID19 crisis), underlying price (which could be high in terms of the human victims and the economy), uncertainty (very high), strike price of option (which could be high in terms of the implementation of the precautionary measures), and riskfree rate (currently low). (Black and Scholes, 1973) These variables show that there are very valuable real options in the COVID-19 crisis.

One path to continuing this research could be to focus on specific decisions and calculate the specific real option val- ues involved in those decisions using for example the BlackScholes option pricing formula. This would afford new perspectives on the evaluation of real options and of any problems that may occur in their application. Possibilities for hedging or insuring against the COVID-19 crisis or similar future crises could also be considered.

\section{NOTES}

1. Structural intellectual capital is innovation capital relating to intellectual assets such as patents and capital tied to organisational processes (Tayles et al., 2007).

\section{ROLE OF THE FUNDING SOURCES}

None of the funding sources had any role in study design; in the collection, analysis and interpretation of the data; in the writing of the report; and in the decision to submit the paper for publication.

\section{ACKNOWLEDGEMENTS}

The authors wish to thank the Emil Aaltonen Foundation for their funding of the research upon which this paper is based. The authors would also like to thank Virginia Mattila for language checking and Thomas Brand, Vikash Sinha and Thomas Taussi for their helpful ideas which motivated the present paper. Thanks are also due to the representatives of the Finnish Government for their handling of the COVID-19 crisis.

\section{CONFLICT OF INTEREST STATEMENT}

The authors declare that they have no conflict of interest.

\section{REFERENCES}

Baldenius, Tim, Alexander A. Nezlobin, and Igor Vaysman. 2016. "Managerial Performance Evaluation and Real Options." The Accounting Review 91(3):741-766.

Black, Fischer and Myron Scholes. 1973. "The Pricing of Options and Corporate Liabilities." The Journal of Political Economy 81(3):637654.

Bowman, Edward H. and Gary T. Moskowitz. 2001. "Real Options Analysis and Strategic Decision Making." Organizations Science 12(6):772777.

Busby, J.S. and C.G.C. Pitts. 1997. "Real Options in Practice: An Exploratory Survey of How Finance Officers Deal with Flexibility in Capital Appraisal." Management Accounting Research 8:169-186.

Das, T.K. and Bing-Sheng Teng. 1999. "Cognitive Biases and Strategic Decision Processes: An Integrative Perspective". Journal of Management Studies 36(6):757-778.

Dixit, Avinash K. and Robert S. Pindyck. 1994. Investment Under Uncertainty. Princeton, NJ: Princeton University Press.

Fair, Jeanne M., Dennis R. Powell, Rene J. LeClaire, Leslie M. Moore, Michael L. Wilson, Lori R. Dauelsberg, Michael E. Samsa, Sharon M. DeLand, Gary B. Hirsch, and Brian W. Bush. 2012. "Measuring the Uncertainties of Pandemic Influenza." International Journal of Risk Assessment and Management 16(1):1-27.

Johnston, Derek M., Stephen E. Sefcik, and Naomi S. Soderstrom. 2008. "The Value Relevance of Greenhouse Gas Emissions Allowances: An Exploratory Study in the Related United States SO2 Market." European Accounting Review 17(4):747-764. 
Jolls, Christine, Cass R. Sunstein, and Richard H. Thaler. 1998. "A Behavioral Approach to Law and Economics." Stanford Law Review 50(5):1471-1550.

Kappes, Andreas, Ann H. Harvey, Terry Lohrenz, P. Read Montague and Tali Sharot. 2020. "Confirmation Bias in the Utilization of Others' Opinion Strength.” Nature Neuroscience 23(1):130-137.

Karr-Wisniewski, Pamela and Ying Lu. 2010. "When More Is Too Much: Operationalizing Technology Overload and Exploring Its Impact on Knowledge Worker Productivity." Computers in Human Behavior 26(5):1061-1072.

McGrath, Rita Gunther and Atul Nerkar. 2004. "Real Options Reasoning and a New Look at the R\&D Investment Strategies of Pharmaceutical Firms." Strategic Management Journal 25:1-21.

Miller, Kent D. and H. Gregory Waller. 2003. "Scenarios, Real Options and Integrated Risk Management." Long Range Planning 36:93-107.

Mun, Johnathan 2006. Real Options Analysis: Tools and Techniques for Valuing Strategic Investments and Decisions. Hoboken, NJ: Wiley, 2nd ed.
Tayles, Mike, Richard H. Pike, and Saudah Sofian. 2007. "Intellectual Capital, Management Accounting Practices and Corporate Performance Perceptions of Managers." Accounting, Auditing \& Accountability Journal 20(4):522-548.

Teece, David and Sohvi Leih. 2016. "Uncertainty, Innovation, and Dynamic Capabilities: An Introduction." California Management Review 58(4):5-12.

Trigeorgis, Lenos. 1995. Real Options in Capital Investment: Models, Strategies, and Applications. Westport, CT: Praeger Publishers.

Verbeeten, Frank H. M. 2006. "Do Organizations Adopt Sophisticated Capital Budgeting Practices to Deal with Uncertainty in the Investment Decision? A Research Note." Management Accounting Research 17:106-120.

Zimmermann, Hans-Jürgen. 2000. "Application-oriented View of Modeling Uncertainty." European Journal of Operational Research 122(2):190-198.

Copyright $\odot$ 2020- All Rights Reserved

This is an open-access article. 